\title{
ORIGINAL
}

\section{Do-not-intubate orders in patients with acute respiratory failure: a systematic review and meta-analysis}

\author{
Michael E. Wilson 1,2,3*${ }^{*}$, Aniket Mittal ${ }^{1}$, Bibek Karki ${ }^{1}$, Claudia C. Dobler²,4,5, Abdul Wahab ${ }^{1}$, J. Randall Curtis ${ }^{6,7}$, \\ Patricia J. Erwin' ${ }^{8}$, Abdul M. Majzoub²,4, Victor M. Montori ${ }^{3,9}$, Ognjen Gajic ${ }^{1}$ and M. Hassan Murad 2,4,9
}

๑ 2019 Springer-Verlag GmbH Germany, part of Springer Nature

\begin{abstract}
Purpose: To assess the rates and variability of do-not-intubate orders in patients with acute respiratory failure.

Methods: We conducted a systematic review of observational studies that enrolled adult patients with acute respiratory failure requiring noninvasive ventilation or high-flow nasal cannula oxygen from inception to 2019.

Results: Twenty-six studies evaluating 10,755 patients were included. The overall pooled rate of do-not-intubate orders was $27 \%$. The pooled rate of do-not-intubate orders in studies from North America was 14\% (range 9-22\%), from Europe was 28\% (range 13-58\%), and from Asia was 38\% (range 9-83\%), $p=0.001$. Do-not-intubate rates were higher in studies with higher patient age and in studies where do-not-intubate decisions were made without reported patient/family input. There were no significant differences in do-not-intubate orders according to illness severity, observed mortality, malignancy comorbidity, or methodological quality. Rates of do-not-intubate orders increased over time from 9\% in 2000-2004 to 32\% in 2015-2019. Only 12 studies (46\%) reported information about do-not-intubate decision-making processes. Only 4 studies (15\%) also reported rates of do-not-resuscitate.

Conclusions: One in four patients with acute respiratory failure (who receive noninvasive ventilation or high-flow nasal cannula oxygen) has a do-not-intubate order. The rate of do-not-intubate orders has increased over time. There is high inter-study variability in do-not-intubate rates-even when accounting for age and illness severity. There is high variability in patient/family involvement in do-not-intubate decision making processes. Few studies reported differences in rates of do-not-resuscitate and do-not-intubate-even though recovery is very different for acute respiratory failure and cardiac arrest.
\end{abstract}

Keywords: Intensive care units, Critical care, Acute respiratory failure, Do-not-intubate, Noninvasive ventilation, Palliative care

\footnotetext{
*Correspondence: wilson.michael1@mayo.edu

${ }^{1}$ Division of Pulmonary and Critical Care Medicine, Mayo Clinic, 200 First Street SW, Rochester, MN 55905, USA
}

Full author information is available at the end of the article

\section{国 Springer}




\section{Introduction}

Acute respiratory failure is a common reason for admission to the intensive care unit (ICU), accounting for approximately one-third of ICU admissions [1-3]. In addition to treating the underlying etiology, the range of supportive treatments for patients with acute respiratory failure includes supplemental oxygen, high-flow nasal cannula oxygen, noninvasive ventilation, invasive mechanical ventilation via endotracheal tube or tracheostomy, extracorporeal membrane oxygenation (ECMO), as well as palliative treatments such as opioids.

While intubation and invasive mechanical ventilation is a cornerstone of supportive treatment for acute respiratory failure, a proportion of patients do not receive invasive mechanical ventilation due to factors such as patient preference for no intubation, physician belief that intubation would not offer any therapeutic benefit (e.g., for a dying patient), or lack of resource availability resulting in triaging ICU beds and ventilators to other patients. A decision to not pursue invasive mechanical ventilation may be reflected in the patient's medical record with a do-not-intubate (DNI) order. Decisions to pursue DNI may occur at any point in a patient's medical course-in the outpatient setting, on the medical ward or emergency department, or when the patient has respiratory failure in the ICU. Such decisions may be revisited when the patient's diagnosis, prognosis, or goals of medical treatment change.

Decisions to place a DNI order may have important consequences for individual patients. While patients with DNI orders have a significantly increased risk of hospital mortality (up to five times greater) compared to patients without DNI orders [4], it remains unclear if this is due to the DNI order or merely a reflection of the increased severity of illness and comorbid conditions in patients for whom a DNI order is placed. Placement of DNI orders and thus withholding of invasive mechanical ventilation may facilitate delivery of treatment that is in agreement with patient preferences and goals [5]. Notwithstanding, more than half of all patients with acute respiratory failure who receive noninvasive ventilation and also have a DNI order survive to hospital discharge-often with no worse quality of life compared to those without a DNI order [4].

While prior studies have identified considerable variability in decisions to withhold or withdraw life support therapies [7-9], the rates of DNI and inter-hospital variability in DNI orders are unknown-especially in patients with acute respiratory failure who are at the highest risk of requiring intubation. Understanding the rates of DNI and DNI-specific variability is an important step in improving DNI decision making. The objectives of this

\section{Take home message}

One in four patients with acute respiratory failure has a do-notintubate order and rates of do-not-intubate orders appear to be increasing over time. There is high inter-study variability in rates of do-not-intubate-even when accounting for age, illness severity, and decision making processes.

study were to (1) assess the rates of DNI in patients with acute respiratory failure and (2) determine if there was inter-study variability in rates of and methods to decide DNI status.

\section{Methods}

We conducted a systematic review of observational studies of adult patients with acute respiratory failure which reported rates of DNI orders. Eligible studies enrolled hospitalized patients who received noninvasive ventilation or high-flow nasal cannula oxygen. The manuscript follows the Preferred Reporting Items for Systematic Reviews and Meta-Analyses (PRISMA) statements [10]. The protocol is registered in the International Prospective Register of Systematic Reviews (PROSPERO \#: CRD42017059914).

\section{Data sources and searches}

We searched CINAHL, PubMed, MICROMEDEX, MEDLINE, EMBASE, Scopus, and Web of Science databases from inception to February 18, 2019 using a medical librarian-designed search strategy (Supplemental Table 1). Independent reviewers, working in pairs, screened the titles, and abstracts of all citations using pre-specified inclusion and exclusion criteria. Studies included by either reviewer were retrieved for full-text screening. Independent reviewers, again working in pairs, screened the full-text version of eligible references. Discrepancies between the reviewers were resolved through consensus. If consensus could not be reached, a third reviewer resolved the difference.

\section{Outcomes measures and analysis}

The primary outcome was rates of DNI. Secondary outcomes were decision-making process to determine DNI and rates of DNR. We conducted subgroup analyses, identified a priori, based on country, patient age $(<60$, $60-75$, and $>75$ years), treatment received (noninvasive ventilation, high flow nasal cannula, both), cancer comorbidity (vs no cancer comorbidity), predicted hospital mortality using severity of illness scores, observed hospital mortality rates, and methodological quality (high vs low). A post hoc analysis was conducted to evaluate the possible change in rate of DNI orders 
over time (publication year categories of 1970-1999, 2000-2004, 2005-2009, 2010-2014, and 2015-2019). Methodological quality of studies was independently assessed by 2 authors using a modified NewcastleOttawa Quality Assessment Scale for cohort studies (Supplemental Table 2) [11]. Pooled estimates were generated using random effects meta-analyses with variance stabilization using the Freeman Turkey double arcsine method [12]. $I^{2}$ was used to estimate variation across studies attributable to heterogeneity. $I^{2}$ ranges from 0 to $100 \%$ with low $I^{2}$ representing low heterogeneity [13]. Two-tailed $p$ value $<0.05$ is considered as statistically significant. All statistical analyses were conducted using Stata/SE version 15.1 (StataCorp LLC, College Station, TX).

\section{Results}

\section{Study characteristics}

Twenty-six unique studies (published in 27 manuscripts) evaluating 10,755 patients with acute respiratory failure were included [6, 14-39]. Supplemental Figure 1 shows the results of search strategy. Table 1 summarizes the characteristics of included studies. Studies were conducted in North America $(n=6)$, Europe $(n=12)$, and Asia $(n=8)$. Mean/median age of patients ranged from 50 to 82 years. Studies treated patients in the ICU, respiratory care units, hospital wards, emergency departments or a combination of these settings. Studies described patients who utilized noninvasive ventilation $(n=17)$, high-flow nasal cannula oxygen $(n=8)$ or both $(n=1)$. Nineteen studies recruited patients with acute respiratory failure of any cause. Seven studies reported results of DNI in cancer patients only. The methodological quality of included studies was high in 9 studies and low in 17 studies (Supplemental Table 3). Sources of low methodological quality included poor sample representativeness (single center studies only), small sample size, no clear distinction between patients with DNI orders and comfort measure only orders, and limited description of the decision making process for DNI orders.

\section{Rates of do-not-intubate orders}

The overall pooled rate of DNI orders was $27 \%$. Rates of DNI from individual studies widely varied and ranged from 9 to $58 \%$. The pooled rate of DNI in studies from North America was 14\% (range 9-22\%), from Europe was 28\% (range 13-58\%), and from Asia was $38 \%$ (range 9-83\%), $p=0.001$ (Fig. 1). The pooled rates of DNI according to age were $20 \%$ (age $<60$ years), $22 \%$ (age 60-75 years), and $49 \%$ (age $\geq 75$ years), $p=0.001$ (Fig. 2).
There were no statistically significant differences in rate of DNI orders based on predicted mortality using severity of illness scores or based on observed mortality rates (Supplemental Figures 2 and 3). There were no statistically significant differences in rates of DNI when looking at studies enrolling cancer patients only vs studies who enrolled patients without cancer $(20 \%$ vs $30 \%)$ or studies using noninvasive ventilation compared to high-flow nasal cannula oxygen (23\% vs $37 \%$ ) (Supplemental Figures 4 and 5). There was also no difference in DNI rates among studies with high vs low methodological quality (Supplemental Figure 6).

The pooled rates of DNI orders increased over time (Fig. 3 and Supplemental Figure 7). For studies published from 2000 to 2004 ( $n=1$ study), the pooled rate of DNI was 9\%. For studies published from 2005 to 2009 ( $n=4$ studies), the pooled rate of DNI was $19 \%$. For studies published from 2010 to 2014 ( $n=7$ studies), the pooled rate of DNI was $26 \%$. For studies published from 2015 to 2019 ( $n=14$ studies), the pooled rate of DNI was $32 \%$.

\section{Methods for decision making}

Only 12 of 26 studies reported information about the decision-making process for DNI (Table 2). Seven studies reported patient or family involvement in decision making and 5 studies reported that patients or families were not involved in the decision making process. Studies, where patients or families were not reported to be involved in DNI decision making, had higher rates of DNI ( $36 \%$ vs $18 \%, p=0.015$ ) (Supplemental Figure 8). Factors reported to be considered when making DNI decisions: age, prognosis, baseline health (functional status, cognition, quality of life, living in a nursing home), patient wishes, family wishes, and comorbidities.

\section{Differentiating do-not-resuscitate from do-not-intubate} Only 4 out of 26 studies also reported a rate of DNR (Table 1). In three studies, the rates of DNR were the same as DNI (i.e., all patients were DNR and DNI). In one study, the reported rate of DNI was $12 \%$ and the reported rate of DNR was 55\% [19].

\section{Discussion}

This systematic review demonstrates several findings. First, 1 in 4 patients who utilize noninvasive ventilation or high-flow nasal cannula for acute respiratory failure has a DNI order. Second, there is high inter-study variability in published rates of DNI orders, even when 
Table 1 Studies reporting rates of do-not-intubate orders of hospitalized patients

\begin{tabular}{|c|c|c|c|c|c|c|c|c|c|}
\hline Study & $\begin{array}{l}\text { Coun- } \\
\text { try }\end{array}$ & $\begin{array}{l}\text { Location } \\
\text { within hos- } \\
\text { pital }\end{array}$ & $\begin{array}{l}\text { Included } \\
\text { only } \\
\text { patients } \\
\text { with can- } \\
\text { cer? }\end{array}$ & $\begin{array}{l}\text { Patients } \\
\text { with DNI } \\
\text { order \% (n) }\end{array}$ & $\begin{array}{l}\text { Patients } \\
\text { with DNR } \\
\text { orders \% } \\
\text { (n) }\end{array}$ & $\begin{array}{l}\text { Reported } \\
\text { patient/family } \\
\text { involvement } \\
\text { in DNI decision } \\
\text { making }\end{array}$ & Age & Severity of illness & $\begin{array}{l}\text { Observed } \\
\text { hospital } \\
\text { mortality } \\
(\%)\end{array}$ \\
\hline $\begin{array}{l}\text { Levy et al. } 2004 \\
\text { [25] }\end{array}$ & USA & ICU, Ward & No & $9 \%(114 / 1211)$ & & Yes & $78(72-84)^{b}(\mathrm{DNI})$ & & 57 \\
\hline $\begin{array}{l}\text { Meert et al. } \\
2005 \text { [14] }\end{array}$ & $\begin{array}{l}\text { Bel- } \\
\text { gium }\end{array}$ & ICU & Yes & $21 \%(18 / 87)$ & & No & $68(29-81)^{b}(\mathrm{DNI})$ & SAPS II: $42(15-58)^{b}$ & \\
\hline $\begin{array}{l}\text { Farha et al. } 2006 \\
\text { [29] }\end{array}$ & USA & Ward & No & $18 \%(14 / 76)$ & & & $63(13)^{\mathrm{a}}$ & & \\
\hline $\begin{array}{l}\text { Bulow et al. } \\
2007 \text { [31], } \\
\text { Bulow and } \\
\text { Thorsager } \\
2009 \text { [30] }\end{array}$ & $\begin{array}{l}\text { Den- } \\
\text { mark }\end{array}$ & ICU & No & $24 \%(38 / 157)$ & & Yes & $\begin{array}{l}73(47-91)^{\mathrm{b}} \\
\text { (DNI hospital } \\
\text { survivors) } \\
73(54-98)^{\mathrm{b}} \text { (DNI } \\
\text { hospital non- } \\
\text { survivors) }\end{array}$ & $\begin{array}{l}\text { APACHE: } 18 \text { (10- } \\
26)^{\mathrm{b}} \text { (DNI hospital } \\
\text { survivors) } \\
21(15-42)^{\mathrm{b}} \text { (DNI } \\
\text { hospital non- } \\
\text { survivors) }\end{array}$ & \\
\hline $\begin{array}{l}\text { Fernandez et al. } \\
2007 \text { [28] }\end{array}$ & Spain & ICU & No & $15 \%(34 / 233)$ & & & $\begin{array}{l}74(9.4)^{\mathrm{a}}(\mathrm{DNI}) \\
67(14.6)^{\mathrm{a}}(\mathrm{full} \\
\text { code) }\end{array}$ & $\begin{array}{l}\text { APACHE II: } \\
20(7.9)^{\mathrm{a}} \text { (DNI) } \\
18(7.1)^{\mathrm{a}} \text { (full code) }\end{array}$ & 34 \\
\hline $\begin{array}{l}\text { Epstein et al. } \\
2011[19]\end{array}$ & USA & ICU, Ward & Yes & $12 \%(22 / 183)$ & $\begin{array}{l}55 \% \\
(101 / 183)\end{array}$ & & $67(20-95)^{b}$ & & 44 \\
\hline $\begin{array}{l}\text { Soler Barnes } \\
\text { et al. } 2011 \\
\text { [23] }\end{array}$ & Spain & ICU & No & $\begin{array}{l}25 \% \\
\quad(658 / 2590)\end{array}$ & & & & & \\
\hline $\begin{array}{l}\text { Schortgen et al. } \\
2012 \text { [24] }\end{array}$ & France & ICU & No & $16 \%(61 / 376)$ & & & & & 44 \\
\hline $\begin{array}{l}\text { Azoulay et al. } \\
2013 \text { [6] }\end{array}$ & $\begin{array}{l}\text { France, } \\
\text { Bel- } \\
\text { gium }\end{array}$ & ICU & No & $\begin{array}{l}26 \% \\
(206 / 780)\end{array}$ & & Yes & $\begin{array}{l}76(65-83)^{b}(\mathrm{DNI}) \\
66(57-76)^{b} \text { (full } \\
\text { code) }\end{array}$ & $\begin{array}{l}\text { SAPS II: 41(35-51) } \\
\text { (DNI) } \\
36(27-47)^{b} \text { (full } \\
\text { code) }\end{array}$ & 18 \\
\hline $\begin{array}{l}\text { La Regina et al. } \\
2013 \text { [27] }\end{array}$ & Italy & Ward & No & $58 \%(85 / 147)$ & & No & $82(47-96)^{a}$ & & 28 \\
\hline $\begin{array}{l}\text { Lemyze et al. } \\
2013 \text { [26] }\end{array}$ & France & ICU & No & $13 \%(74 / 573)$ & & Yes & $75(64-80)^{b}(\mathrm{DNI})$ & SAPS II: $40(35-49)^{b}$ & 23 \\
\hline $\begin{array}{l}\text { Del Campo } \\
\text { Molina et al. } \\
2014 \text { [22] }\end{array}$ & Spain & $\mathrm{RCU}$ & No & $45 \%(95 / 211)$ & $\begin{array}{l}45 \% \\
(95 / 211)\end{array}$ & No & $78(41-97)^{a}$ & $\begin{array}{l}\text { APACHE II: } \\
\text { 18(12-33) }\end{array}$ & 32 \\
\hline $\begin{array}{l}\text { Bugov et al. } \\
2015 \text { [17] }\end{array}$ & USA & ICU, Ward & Yes & $22 \%(8 / 36)$ & $22 \%(8 / 36)$ & & $54(19)^{\mathrm{a}}$ & & 31 \\
\hline $\begin{array}{l}\text { Lee et al. } 2015 \\
\text { [16] }\end{array}$ & $\begin{array}{l}\text { South } \\
\text { Korea }\end{array}$ & ICU, Ward & Yes & $14 \%(7 / 52)$ & & & $50(2)^{a}$ & APACHE II: $17(0.6)^{\mathrm{a}}$ & 62 \\
\hline $\begin{array}{l}\text { Durey et al. } \\
2016 \text { [15] }\end{array}$ & $\begin{array}{l}\text { South } \\
\text { Korea }\end{array}$ & ED & Yes & $36 \%(4 / 11)$ & & & $72(10.6)^{a}$ & APACHE II: $23(4)^{\mathrm{a}}$ & 36 \\
\hline $\begin{array}{l}\text { Harada et al. } \\
2016 \text { [18] }\end{array}$ & Japan & & Yes & $41 \%(23 / 56)$ & & & $59(24-82)^{b}$ & SAPS II: $43(14-88)^{b}$ & \\
\hline $\begin{array}{l}\text { Ugurlu et al. } \\
2016 \text { [21] }\end{array}$ & USA & ICU, Ward, ED & No & 19\% (97/499) & & & & & \\
\hline $\begin{array}{l}\text { Vilaca et al. } \\
2016 \text { [20] }\end{array}$ & $\begin{array}{l}\text { Portu- } \\
\text { gal }\end{array}$ & ED & No & $29 \%(70 / 243)$ & & No & $82(75-87)^{b}(\mathrm{DNI})$ & & 57 \\
\hline $\begin{array}{l}\text { Hibi et al. } 2017 \\
\text { [34] }\end{array}$ & Japan & & No & $\begin{array}{l}38 \% \\
\quad(188 / 495)\end{array}$ & & & & & \\
\hline $\begin{array}{l}\text { Duan et al. } 2018 \\
\text { [33] }\end{array}$ & China & ICU & No & $9 \%(140 / 1539)$ & & Yes & $\begin{array}{l}69(14)^{\mathrm{a}} \\
(\mathrm{NIV}<14 \text { days }) \\
72(14)^{\mathrm{a}} \\
(\mathrm{NIV} \geq 14 \text { days })\end{array}$ & $\begin{array}{c}\text { APACHE II: } 16(4)^{\mathrm{a}} \\
(\mathrm{NIV}<14 \text { days }) \\
17(4)^{\mathrm{a}} \\
(\mathrm{NIV} \geq 14 \text { days })\end{array}$ & 17 \\
\hline $\begin{array}{l}\text { Ito et al. } 2018 \\
\text { [37] }\end{array}$ & Japan & ICU, Ward, ED & No & $\begin{array}{l}37 \% \\
\quad(120 / 321)\end{array}$ & & & $76(66-83)^{b}$ & & 36 \\
\hline $\begin{array}{l}\text { Kang et al. } 2018 \\
\text { [39] }\end{array}$ & $\begin{array}{l}\text { South } \\
\text { Korea }\end{array}$ & ICU, Ward & No & $55 \%(50 / 91)$ & & & $65(12)^{\mathrm{a}}$ & APACHE II: $22(5)^{\mathrm{a}}$ & 63 \\
\hline
\end{tabular}


Table 1 (continued)

\begin{tabular}{|c|c|c|c|c|c|c|c|c|c|}
\hline Study & $\begin{array}{l}\text { Coun- } \\
\text { try }\end{array}$ & $\begin{array}{l}\text { Location } \\
\text { within hos- } \\
\text { pital }\end{array}$ & $\begin{array}{l}\text { Included } \\
\text { only } \\
\text { patients } \\
\text { with can- } \\
\text { cer? }\end{array}$ & $\begin{array}{l}\text { Patients } \\
\text { with DNI } \\
\text { order \% (n) }\end{array}$ & $\begin{array}{l}\text { Patients } \\
\text { with DNR } \\
\text { orders \% } \\
\text { (n) }\end{array}$ & $\begin{array}{l}\text { Reported } \\
\text { patient/family } \\
\text { involvement } \\
\text { in DNI decision } \\
\text { making }\end{array}$ & Age & Severity of illness & $\begin{array}{l}\text { Observed } \\
\text { hospital } \\
\text { mortality } \\
(\%)\end{array}$ \\
\hline $\begin{array}{c}\text { Makino et al. } \\
2018 \text { [38] }\end{array}$ & Japan & & No & $83 \%(48 / 58)$ & & & $78^{\mathrm{a}}$ & & 50 \\
\hline $\begin{array}{c}\text { Brambilla et al. } \\
2019 \text { [35] }\end{array}$ & Italy & $\begin{array}{r}\text { ED, Respira- } \\
\text { tory ward }\end{array}$ & No & $\begin{array}{l}30 \% \\
\quad(103 / 347)\end{array}$ & & No & $\begin{array}{l}77(66-85)^{b} \\
74(14)^{\mathrm{a}}\end{array}$ & APACHE II: $18(6)^{\mathrm{a}}$ & 24 \\
\hline $\begin{array}{l}\text { Hedsund et al. } \\
2019 \text { [36] }\end{array}$ & $\begin{array}{l}\text { Den- } \\
\text { mark }\end{array}$ & Ward & No & $\begin{array}{l}49 \% \\
\quad(141 / 304)\end{array}$ & $\begin{array}{l}49 \% \\
\quad(141 / 304)\end{array}$ & Yes & $76^{\mathrm{a}}$ & & 30 \\
\hline $\begin{array}{l}\text { Liu et al. } 2019 \\
\text { [32] }\end{array}$ & Canada & ICU & Yes & $9 \%(7 / 79)$ & & Yes & $56(14)^{a}$ & APACHE II: $28(5)^{\mathrm{a}}$ & 41 \\
\hline
\end{tabular}

All values are for entire cohort (Full Code + DNI patients) unless otherwise specified. Blank boxes signify the result was not reported

$D N I$ do not intubate, DNR do not resuscitate, ICU intensive care unit, NIV noninvasive ventilation, HFNC high-flow nasal cannula, $R C U$ respiratory care unit, ED emergency department, USA United States of America

a Mean (standard deviation)

b Median (interquartile range)

accounting for factors such as age, country, and illness severity. Third, there is high variability in the reported decision-making processes of individual studies to determine DNI. Fourth, few studies reported differences in rates of DNR and DNI-even though chances for recovery are better for acute respiratory failure compared with cardiac arrest. Fifth, published rates of DNI increased over time from $9 \%$ in $2000-2004$ to $32 \%$ in 2015-2019.

Variability in DNI orders according to global location may reflect differences in policies, practices, medical ethics, social attitudes, culture, and religion [7, 40-42]. Characteristics of patients, families, physicians, and hospitals (including ethical climates, implementation of advance care planning, as well as availability of ICU beds and ventilators) also play important roles [7, 8, 43-58]. A recent global analysis of clinicians' views on ethical aspects of withholding and withdrawing life support showed that although there are important differences between countries and hospitals within a country, the largest differences are accounted for by differences between individual clinicians within a hospital [40]. Increasing rates of DNI orders over the past 20 years may reflect increased focus on high quality end-of-life care, changing ethical climates $[55,56]$, or increased recognition of the utility of noninvasive ventilation in patients who are not candidates for intubation. Higher rates of DNI orders in Europe and Asia (compared to North America) could also reflect these same principles (e.g., increased physician anticipation of end-of-life).
Patients with DNI orders have variable goals of care (ranging from curative intent to solely symptom relief). Therefore, it is important to evaluate DNI orders in the context other potential treatment limitations such as DNR orders or orders to stop all life-prolonging treatments such as antibiotics, dialysis, surgery, etc. ("comfort measures only"). Shared decision making, a collaborative decision-making process involving both physician and patient/family input, has been endorsed by a panel of experts from 32 countries worldwide [59]. Nevertheless, integration of shared decision making into practice is variable and there are few tools to help clinicians, patients, and families. In some settings, written DNI orders may not accurately reflect patient wishes-as some patients with written DNI orders may actually prefer a trial of intubation as long as the ventilator would be withdrawn if intubation becomes prolonged [60]. Nevertheless, in countries where life support withdrawal may be culturally unacceptable or even illegal, there may be a greater tendency to avoid intubation altogether.

Our manuscript has several limitations. First, there was significant heterogeneity of included studies and we were methodologically unable to perform a multivariate analysis. Second, we could not account for institutional variation in multi-center studies which reported pooled estimates only. Third, data regarding patient/family involvement may be limited as reporting these data was not a primary purpose of many included studies. Fourth, we presented observational data only and did not evaluate the association of DNI status or treatments used on 


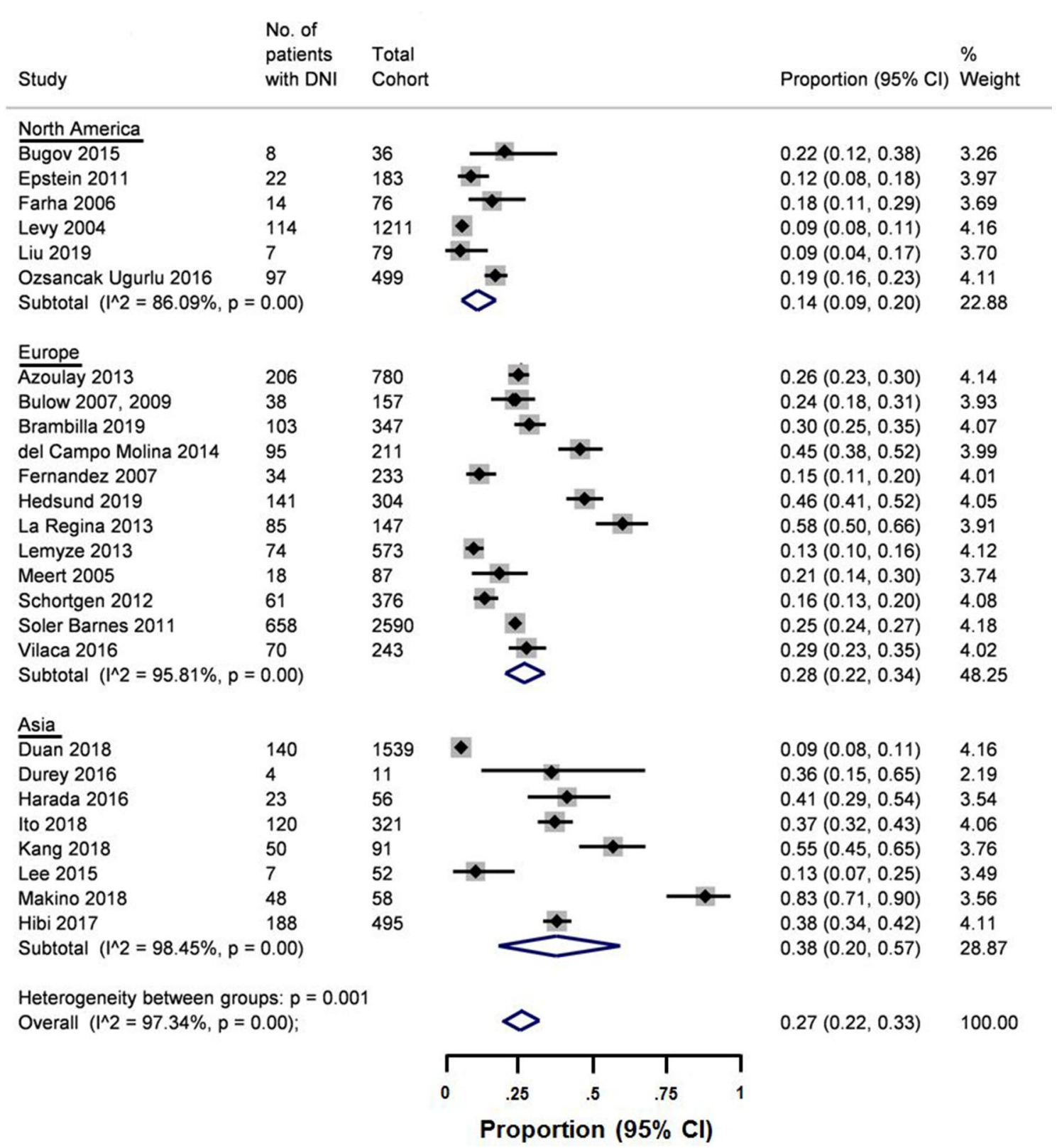

Fig. 1 Rates of do-not-intubate orders in patients with acute respiratory failure according to study location. The diamond under each subgroup represents the pooled proportion of patients with do-not-intubate (DNI) orders. The width of the diamond represents the $95 \%$ confidence interval (Cl) of the pooled proportion

clinical outcomes. Fifth, study results may not generalize to institutions, where such epidemiological studies have not been performed. Sixth, DNI rates may be different in patients who were not receiving noninvasive ventilation or high-flow nasal cannula oxygen. Seventh, evaluations for characteristics such as patient age and illness severity were based on study population means, as we were unable to perform individual patient data analysis. Eighth, $65 \%$ of included studies were of low methodological quality; nevertheless, there were no significant DNI rate differences based on quality. 


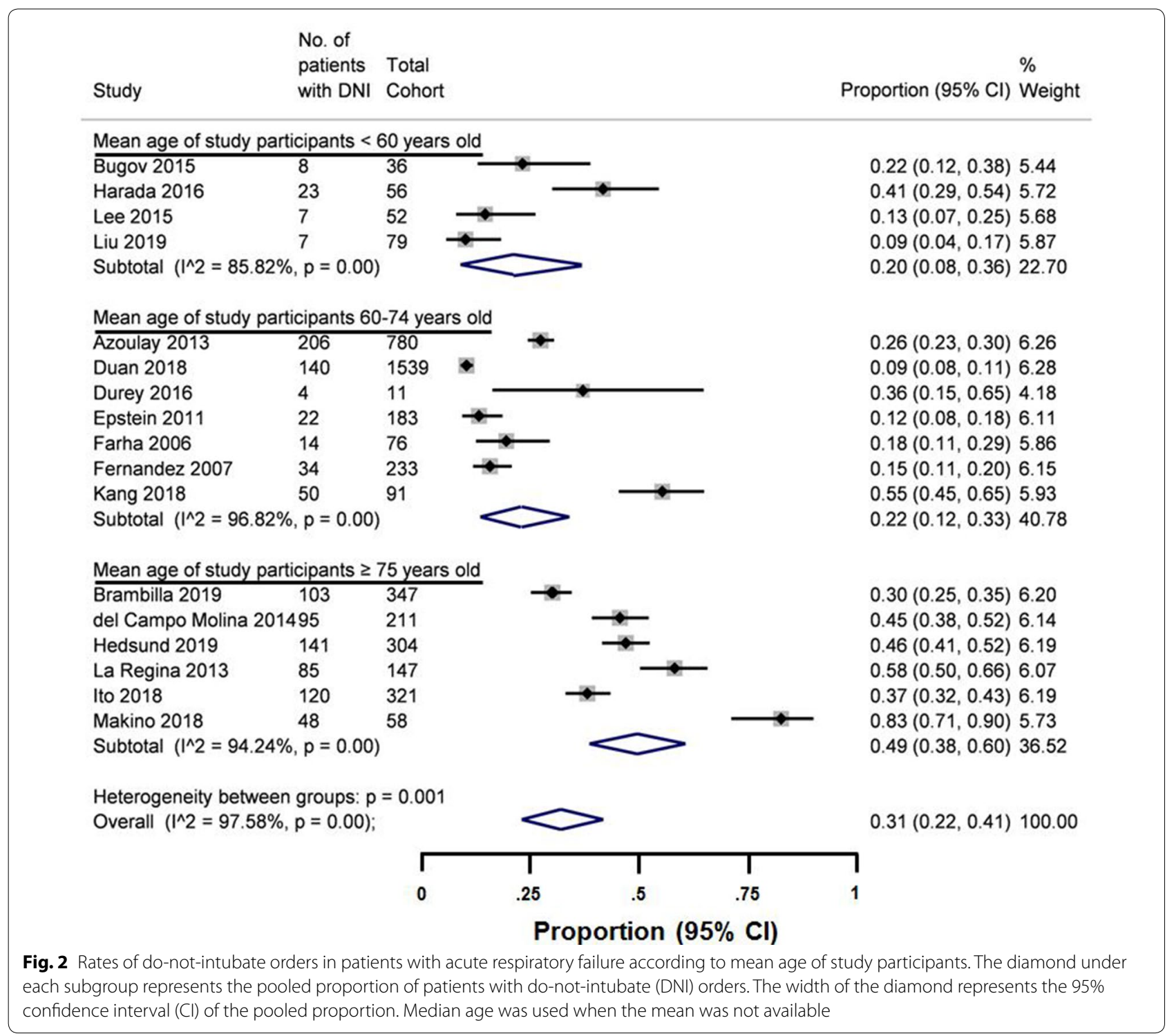

In conclusion, while this manuscript builds on the previous work to categorize DNI-specific variability, significant work remains to explore the non-physiological indications for clinician choice to provide noninvasive oxygenation support to patients in respiratory failure. Future considerations also include evaluating the impact of DNI orders and treatments (e.g., noninvasive ventilation) on short- and long-term outcomes when adjusted for individual patient characteristics, as well as the development and testing of interventions to improve DNI decision making. Truly understanding DNI variability across continents can only be achieved by benchmarking long-term outcomes in patients with and without DNI orders across geographical regions, cultures, and ethical climates. 


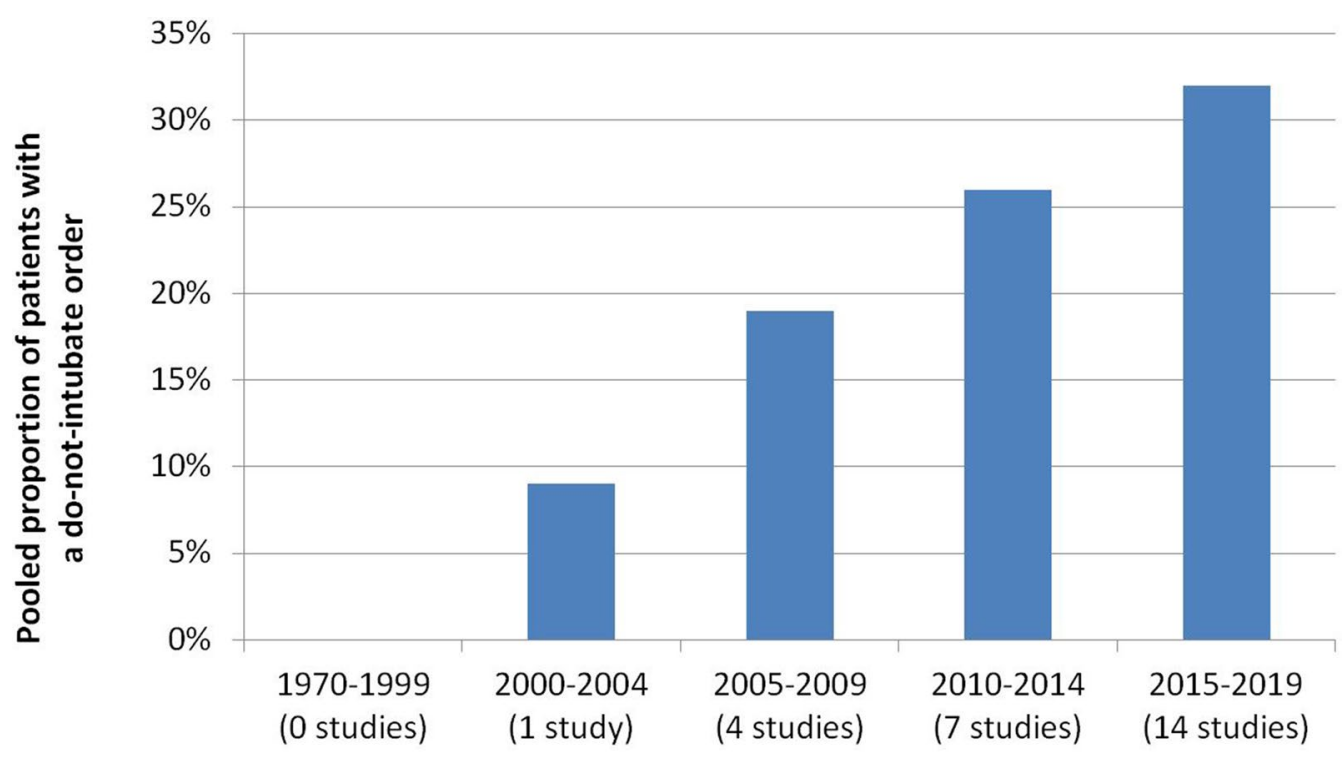

\section{Year of publication}

Fig. 3 Rates of do-not-intubate orders in patients with acute respiratory failure according to publication year

\section{Table 2 Description of do-not-intubate decision-making process}

\begin{tabular}{|c|c|c|}
\hline Study & Country & Description of DNI decision making process \\
\hline La Regina et al. [27] & Italy & $\begin{array}{l}\text { "We considered DNI patients to be those of advanced age, bed-ridden, with severe cognitive impairment, and/or } \\
\text { severe and multiple comorbidities and/or short life expectancy." }\end{array}$ \\
\hline $\begin{array}{l}\text { Del Campo Molina } \\
\text { et al. [22] }\end{array}$ & Spain & $\begin{array}{l}\text { DNI was based on physician assessment of "age, comorbidities, or poor prognosis." DNI status was then "reported to } \\
\text { the family." }\end{array}$ \\
\hline Vilaca et al. [20] & Portugal & $\begin{array}{l}\text { "Withholding therapy decision" group, comprised patients for whom a decision was made by the attending physi- } \\
\text { cian not to start or increase a life-sustaining intervention." }\end{array}$ \\
\hline Azoulay et al. [6] & $\begin{array}{l}\text { France, } \\
\text { Belgium }\end{array}$ & $\begin{array}{l}\text { DNI was defined as "patients who themselves declined tracheal intubation and those in whom the healthcare staff } \\
\text { considered that tracheal intubation was not appropriate" }\end{array}$ \\
\hline $\begin{array}{l}\text { Bulow et al. [31], } \\
\text { Bulow and } \\
\text { Thorsager [30] }\end{array}$ & Denmark & $\begin{array}{l}\text { "The reasons for DNI orders were patient's own wish, or very low pulmonary capacity, very low physical ability at } \\
\text { home with a low quality of life, referred from a nursing home, concomitant severe disease with a low life expect- } \\
\text { ance and often a combination of these reasons." }\end{array}$ \\
\hline Lemyze et al. [26] & France & $\begin{array}{l}\text { "This decision was made by the patient himself whenever possible, or by a multidisciplinary team including physi- } \\
\text { cians and nurses caring for the patient when the latter does not have the capacity to make such a decision. Clini- } \\
\text { cians involved in the decision process included at least an intensivist and either a pulmonologist or a cardiologist, } \\
\text { who did not participate in the present study. Patients were classified as do-not-intubate when their physical dis- } \\
\text { ability and their underlying debilitating conditions made them poor candidates for intubation. The patient's family } \\
\text { was informed in a clear and loyal manner, and all efforts were provided to make them understand and adhere to } \\
\text { the medical decision." }\end{array}$ \\
\hline Levy et al. [25] & USA & $\begin{array}{l}\text { "23 of the DNI patients had advanced directives and had declared their wishes prior to admission, and the remainder } \\
\text { had their DNI status established following admission." }\end{array}$ \\
\hline Brambilla et al. [35] & Italy & $\begin{array}{l}\text { "Do Not Intubate (DNI) order was defined as the decision of the physician in charge to withhold intubation and to } \\
\text { use NIV as "ceiling" treatment considering the characteristics of the patients (e.g., extremely poor functional status } \\
\text { prior on admission, very low predicted probability of hospital survival)" }\end{array}$ \\
\hline Hedsund et al. [36] & Denmark & $\begin{array}{l}\text { "DNR/DNI orders were placed after assessment of the patient's general daily activity level and functional impairment, } \\
\text { severity of disease, comorbid conditions, and patient's own wish and with less consideration to the course of cur- } \\
\text { rent treatment. Senior physicians were always consulted and if possible, the patient and their relatives too." }\end{array}$ \\
\hline Duan et al. [33] & China & $\begin{array}{l}\text { "A do-not-intubate (DNI) order can be made at ICU admission or at NIV as a first-line treatment failure. It was decided } \\
\text { by patients themselves or their families." }\end{array}$ \\
\hline Meert et al. [14] & Belgium & $\begin{array}{l}\text { "The staff consisting of physicians, including intensivists, decides this [life support limitation order] during regular } \\
\text { meetings in the department." }\end{array}$ \\
\hline Liu et al. [32] & Canada & $\begin{array}{l}\text { "We included patients who had a do-not-intubation (DNI) advance directive at the time of NIV initiation or whose } \\
\text { goals of care were changed to DNI during ICU admission." }\end{array}$ \\
\hline
\end{tabular}




\section{Electronic supplementary materia}

The online version of this article (https://doi.org/10.1007/s00134-019-05828-2) contains supplementary material, which is available to authorized users.

\section{Author details}

${ }^{1}$ Division of Pulmonary and Critical Care Medicine, Mayo Clinic, 200 First Street SW, Rochester, MN 55905, USA. ${ }^{2}$ Robert D. and Patricia E. Kern Center for the Science of Health Care Delivery, Mayo Clinic, Rochester, MN, USA.

${ }^{3}$ Knowledge and Evaluation Research Unit, Mayo Clinic, Rochester, MN, USA. ${ }^{4}$ Evidence-Based Practice Center, Mayo Clinic, Rochester, MN, USA. ${ }^{5}$ Institute for Evidence-Based Healthcare, Bond University and Gold Coast University Hospital, Gold Coast, QLD, Australia. ${ }^{6}$ Division of Pulmonary and Critical Care Medicine, Harborview Medical Center, University of Washington, Seattle, WA, USA. ${ }^{7}$ Cambia Palliative Care Center of Excellence, University of Washington, Seattle, WA, USA. ${ }^{8}$ Medical Library, Mayo Clinic, Rochester, MN, USA. ${ }^{9}$ Department of Medicine, Mayo Clinic, Rochester, MN, USA.

\section{Funding}

This project received no funding.

\section{Compliance with ethical standards}

\section{Conflicts of interest}

The authors have no conflicts of interest to disclose.

\section{Publisher's Note}

Springer Nature remains neutral with regard to jurisdictional claims in published maps and institutional affiliations.

Received: 26 August 2019 Accepted: 7 October 2019

Published online: 28 October 2019

\section{References}

1. Wunsch H, Angus DC, Harrison DA, Linde-Zwirble WT, Rowan KM (2011) Comparison of medical admissions to intensive care units in the United States and United Kingdom. Am J Respir Crit Care Med 183(12):1666-1673

2. Vincent JL, Akca S, De Mendonca A, Haji-Michael P, Sprung C, Moreno R, Antonelli M, Suter PM (2002) The epidemiology of acute respiratory failure in critically ill patients. Chest 121(5):1602-1609

3. Wunsch H, Wagner J, Herlim M, Chong DH, Kramer AA, Halpern SD (2013) ICU occupancy and mechanical ventilator use in the United States. Crit Care Med 41(12):2712-2719

4. Wilson ME, Majzoub AM, Dobler CC, Curtis JR, Nayfeh T, Thorsteinsdottir B, Barwise AK, Tilburt JC, Gajic O, Montori VM, Murad MH (2018) Noninvasive ventilation in patients with do-not-intubate and comfort-measuresonly orders: a systematic review and meta-analysis. Crit Care Med 46(8):1209-1216

5. Curtis JR, Cook DJ, SinuffT, White DB, Hill N, Keenan SP, Benditt JO, Kacmarek R, Kirchhoff KT, Levy MM (2007) Noninvasive positive pressure ventilation in critical and palliative care settings: understanding the goals of therapy. Crit Care Med 35(3):932-939

6. Azoulay E, Kouatchet A, Jaber S, Lambert J, Meziani F, Schmidt M, Schnell D, Mortaza S, Conseil M, Tchenio X, Herbecq P, Andrivet P, Guerot E, Lafabrie A, Perbet S, Camous L, Janssen-Langenstein R, Collet F, Messika J, Legriel S, Fabre X, Guisset O, Touati S, Kilani S, Alves M, Mercat A, Similowski T, Papazian L, Meert AP, Chevret S, Schlemmer B, Brochard L, Demoule A (2013) Noninvasive mechanical ventilation in patients having declined tracheal intubation. Intensive Care Med 39(2):292-301

7. Quill CM, Ratcliffe SJ, Harhay MO, Halpern SD (2014) Variation in decisions to forgo life-sustaining therapies in US ICUs. Chest 146(3):573-582

8. Hart JL, Harhay MO, Gabler NB, Ratcliffe SJ, Quill CM, Halpern SD (2015) Variability among us intensive care units in managing the care of patients admitted with preexisting limits on life-sustaining therapies. JAMA internal Med 175(6):1019-1026

9. Garland A, Connors AF (2007) Physicians' influence over decisions to forego life support. J Palliat Med 10(6):1298-1305
10. Moher D, Liberati A, Tetzlaff J, Altman DG (2009) Preferred reporting items for systematic reviews and meta-analyses: the PRISMA statement. BMJ (Clin Res ed) 339:b2535

11. Wells $G$, Shea B, O'Connell D, Peterson J, Welch V, Losos M, Tugwell P (2009) The Newcastle-Ottawa Scale (NOS) for assessing the quality of nonrandomized studies in meta-analyses. The Ottawa Hospital Research Institute. http://www.ohri.ca/programs/clinical_epidemiology/oxfor d.htm. Accessed 26 Aug 2019

12. Barendregt JJ, Doi SA, Lee YY, Norman RE, Vos T (2013) Meta-analysis of prevalence. J Epidemiolog Community Health 67(11):974-978

13. Riley RD, Higgins JP, Deeks JJ (2011) Interpretation of random effects meta-analyses. BMJ (Clin Res Ed) 342:d549

14. Meert AP, Berghmans T, Hardy M, Markiewicz E, Sculier JP (2006) Noninvasive ventilation for cancer patients with life-support techniques limitation. Support Care Cancer 14(2):167-171

15. Durey A, Kang S, Paik JH, Han SB, Kim AJ (2016) Application of high-flow nasal cannula in the ED for patients with solid malignancy. Am J Emerg Med 34(11):2222-2223

16. Lee HY, Rhee CK, Lee JW (2015) Feasibility of high-flow nasal cannula oxygen therapy for acute respiratory failure in patients with hematologic malignancies: a retrospective single-center study. J Crit Care 30(4):773-777

17. Bugov D, Voigt LP, Yohannes-Tomicich J, Abbas Q, Tayban Y, Weiner R, Kostelecky N, Ramaker JS, Kirnicinii G, Haynes A (2015) High-flow nasal cannula oxygenation in cancer patients: practice patterns and outcomes. Chest 148(4):301A

18. Harada K, Kurosawa S, Hino Y, Yamamoto K, Sakaguchi M, Ikegawa S, Hattori K, Igarashi A, Watakabe K, Senoo Y (2016) Clinical utility of high-flow nasal cannula oxygen therapy for acute respiratory failure in patients with hematological disease. Springerplus 5(1):512

19. Epstein AS, Hartridge-Lambert SK, Ramaker JS, Voigt LP, Portlock CS (2011) Humidified high-flow nasal oxygen utilization in patients with cancer at Memorial Sloan-Kettering Cancer Center. J Palliat Med 14(7):835-839

20. Vilaça M, Aragão I, Cardoso T, Dias C, Cabral-Campello G (2016) The role of noninvasive ventilation in patients with "do not intubate" order in the emergency setting. PLoS One 11(2):e0149649

21. Ugurlu AO, Sidhom SS, Khodabandeh A, leong M, Mohr C, Lin DY, Buchwald I, Bahhady I, Wengryn J, Maheshwari V (2016) Use and outcomes of noninvasive ventilation for acute respiratory failure in different age groups. Respir Care 61(1):36-43

22. Del Campo Molina E, Angel P, Garcia Delgado F, Artacho Ruiz R, Guzman Perez J, Fernandez Romero E, Caballero Gueeto F (2014) Is it ethical to use non-invasive mechanical ventilation (NIMV) in patients considered as to be under limitation of therapeutic efforts (LTE)? Intensive Care Med 40:S76-S77

23. Soler Barnes J, Carrillo Alcaraz A, Gonzalez Diaz G, Botias Arnau S, Lopez Martinez A, Alcazar Espin M, Llamas Fernandez N (2011) aaDo-not-intubated (DNI) order and non-invasive mechanical ventilation (NIMV). Crit Care Long Term Surviv Intensive Care Med 37:S69

24. Schortgen F, Follin A, Piccari L, Roche-Campo F, Carteaux G, TaillandierHeriche E, Krypciak S, Thille AW, Paillaud E, Brochard L (2012) Results of noninvasive ventilation in very old patients. Ann Intensive Care 2(1):5

25. Levy M, Tanios MA, Nelson D, Short K, Senechia A, Vespia J, Hill NS (2004) Outcomes of patients with do-not-intubate orders treated with noninvasive ventilation. Crit Care Med 32(10):2002-2007

26. Lemyze M, Mallat J, Nigeon O, Barrailler S, Pepy F, Gasan G, Vangrunderbeeck N, Grosset P, Tronchon L, Thevenin D (2013) Rescue therapy by switching to total face mask after failure of face mask-delivered noninvasive ventilation in do-not-intubate patients in acute respiratory failure. Crit Care Med 41(2):481-488

27. La Regina M, Marinaro A, Scuotri L, Corsini F, Orlandini F (2013) Noninvasive mechanical ventilation in internal medicine departments: a pilot study. Ital J Med 7(3):172-178

28. Fernandez R, Baigorri F, Artigas A (2007) Noninvasive ventilation in patients with "do-not-intubate" orders: medium-term efficacy depends critically on patient selection. Intensive Care Med 33(2):350-354

29. Farha S, Ghamra ZW, Hoisington ER, Butler RS, Stoller JK (2006) Use of noninvasive positive-pressure ventilation on the regular hospital ward: experience and correlates of success. Respir Care 51(11):1237-1243 
30. Bulow HH, Thorsager B (2009) Non-invasive ventilation in do-not-intubate patients: five-year follow-up on a two-year prospective, consecutive cohort study. Acta Anaesthesiol Scand 53(9):1153-1157

31. Bulow HH, Thorsager B, Hoejberg JM (2007) Experiences from introducing non-invasive ventilation in the intensive care unit: a 2-year prospective consecutive cohort study. Acta Anaesthesiol Scand 51(2):165-170

32. Liu JJ, Bell C, Campbell V, DeBacker J, Tamberg E, Lee C, Mehta S (2019) Noninvasive ventilation in patients with hematologic malignancy: a retrospective study. J Intensive Care Med 34(3):197-203

33. Duan J, Bai L, Zhou L, Han X, Jiang L, Huang S (2018) Resource use, characteristics and outcomes of prolonged non-invasive ventilation: a single-centre observational study in China. BMJ Open 8(12):e019271

34. Hibi M, Shiraki A, Nagata K, Nei Y, Sato S, Nishimura N, Izumi S, Tachikawa R, Tomii K (2017) Comparison between high-flow nasal cannula oxygen therapy and non-invasive ventilation for respiratory care: a Japanese cross-sectional multicenter survey. Eur Respir J Conf Eur Respir Soc Int Congress ERS 50 (Supplement 61):PA1876

35. Brambilla AM, Prina E, Ferrari G, Bozzano V, Ferrari R, Groff P, Petrelli G, Scala R, Causin F, Noto P, Bresciani E, Voza A, Aliberti S, Cosentini R, Group PS (2019) Non-invasive positive pressure ventilation in pneumonia outside Intensive Care Unit: an Italian multicenter observational study. European Journal of Internal Medicine 59:21-26

36. Hedsund C, Ankjaergaard KL, Rasmussen DB, Schwaner SH, Andreassen HF, Hansen EF, Wilcke JT (2019) NIV for acute respiratory failure in COPD: high in-hospital mortality is determined by patient selection. Eur Clin Respir J 6(1):1571332

37. Ito J, Nagata K, Sato S, Shiraki A, Nishimura N, Izumi S, Tachikawa R, Morimoto T, Tomii K (2018) The clinical practice of high-flow nasal cannula oxygen therapy in adults: a Japanese cross-sectional multicenter survey. Respir Investig 56(3):249-257

38. Makino H, Nishikawa H, Taguchi Y, Kouda T, Kajiwara K, Kanematsu T (2018) Can high-flow nasal cannula improve comfort in elderly patients with acute respiratory failure? Am J Respir Crit Care Med Conf Am Thorac Soc Int Conf ATS 197 (MeetingAbstracts):A3249

39. Kang YS, Choi SM, Lee J, Park YS, Lee CH, Yoo CG, Kim YW, Han SK, Lee SM (2018) Improved oxygenation 48 hours after high-flow nasal cannula oxygen therapy is associated with good outcome in immunocompromised patients with acute respiratory failure. J Thorac Dis 10(12):6606-6615

40. Long AC, Brumback LC, Curtis JR, Avidan A, Baras M, De Robertis E, Efferen L, Engelberg RA, Kross EK, Michalsen A, Mularski RA, Sprung CL (2019) Agreement with consensus statements on end-of-life care: a description of variability at the level of the provider, Hospital, and Country. Crit Care Med

41. Santonocito C, Ristagno G, Gullo A, Weil MH (2013) Do-not-resuscitate order: a view throughout the world. J Crit Care 28(1):14-21

42. Shen MJ, Prigerson HG, Paulk E, Trevino KM, Penedo FJ, Tergas Al, Epstein AS, Neugut Al, Maciejewski PK (2016) Impact of end-of-life discussions on the reduction of Latino/non-Latino disparities in do-not-resuscitate order completion. Cancer 122(11):1749-1756

43. Pochard F, Azoulay E, Chevret S, Vinsonneau C, Grassin M, Lemaire F, Herve C, Schlemmer B, Zittoun R, Dhainaut JF (2001) French intensivists do not apply American recommendations regarding decisions to forgo life-sustaining therapy. Crit Care Med 29(10):1887-1892

44. Romain M, Sprung CL (2014) End-of-life practices in the intensive care unit: the importance of geography, religion, religious affiliation, and culture. Rambam Maimonides Med J 5(1):e0003

45. Barnato AE, Herndon MB, Anthony DL, Gallagher PM, Skinner JS, Bynum JP, Fisher ES (2007) Are regional variations in end-of-life care intensity explained by patient preferences?: A study of the US medicare population. Med Care 45(5):386-393
46. Chen LM, Render M, Sales A, Kennedy EH, Wiitala W, Hofer TP (2012) Intensive care unit admitting patterns in the Veterans Affairs health care system. Arch Intern Med 172(16):1220-1226

47. Angus DC, Barnato AE, Linde-Zwirble WT, Weissfeld LA, Watson RS, Rickert T, Rubenfeld GD (2004) Use of intensive care at the end of life in the United States: an epidemiologic study. Crit Care Med 32(3):638-643

48. Wennberg JE, Fisher ES, Stukel TA, Skinner JS, Sharp SM, Bronner KK (2004) Use of hospitals, physician visits, and hospice care during last six months of life among cohorts loyal to highly respected hospitals in the United States. BMJ (Clin Res Ed) 328(7440):607

49. Seymour CW, Iwashyna TJ, Ehlenbach WJ, Wunsch H, Cooke CR (2012) Hospital-level variation in the use of intensive care. Health Serv Res 47(5):2060-2080

50. DeCato TW, Engelberg RA, Downey L, Nielsen EL, Treece PD, Back AL, Shannon SE, Kross EK, Curtis JR (2013) Hospital variation and temporal trends in palliative and end-of-life care in the ICU. Crit Care Med $41(6): 1405-1411$

51. Lin CY, Farrell MH, Lave JR, Angus DC, Barnato AE (2009) Organizational determinants of hospital end-of-life treatment intensity. Med Care 47(5):524-530

52. Barnato AE, Bost JE, Farrell MH, Lave JR, Arnold RM, Rubio DM, Angus DC (2007) Relationship between staff perceptions of hospital norms and hospital-level end-of-life treatment intensity. J Palliat Med 10(5):1093-1100

53. Mark NM, Rayner SG, Lee NJ, Curtis JR (2015) Global variability in withholding and withdrawal of life-sustaining treatment in the intensive care unit: a systematic review. Intensive Care Med 41(9):1572-1585

54. Wilson ME, Rhudy LM, Ballinger BA, Tescher AN, Pickering BW, Gajic O (2013) Factors that contribute to physician variability in decisions to limit life support in the ICU: a qualitative study. Intensive Care Med 39(6):1009-1018

55. Baskett PJ, Lim A (2004) The varying ethical attitudes towards resuscitation in Europe. Resuscitation 62(3):267-273

56. Mentzelopoulos SD, Bossaert L, Raffay V, Askitopoulou H, Perkins GD, Greif R, Haywood K, Van de Voorde P, Xanthos T (2016) A survey of key opinion leaders on ethical resuscitation practices in 31 European Countries. Resuscitation 100:11-17

57. Yadav KN, Gabler NB, Cooney E, Kent S, Kim J, Herbst N, Mante A, Halpern SD, Courtright KR (2017) Approximately one in three US adults completes any type of advance directive for end-of-life care. Health Aff (Project Hope) 36(7):1244-1251

58. Benoit DD, Jensen HI, Malmgren J, Metaxa V, Reyners AK, Darmon M, Rusinova K, Talmor D, Meert AP, Cancelliere L, Zubek L, Maia P, Michalsen A, Vanheule S, Kompanje EJO, Decruyenaere J, Vandenberghe S, Vansteelandt S, Gadeyne B, Van den Bulcke B, Azoulay E, Piers RD (2018) Outcome in patients perceived as receiving excessive care across different ethical climates: a prospective study in 68 intensive care units in Europe and the USA. Intensive Care Med 44(7):1039-1049

59. Sprung CL, Truog RD, Curtis JR, Joynt GM, Baras M, Michalsen A, Briegel J, Kesecioglu J, Efferen L, De Robertis E, Bulpa P, Metnitz P, Patil N, Hawryluck L, Manthous C, Moreno R, Leonard S, Hill NS, Wennberg E, McDermid RC, Mikstacki A, Mularski RA, Hartog CS, Avidan A (2014) Seeking worldwide professional consensus on the principles of end-of-life care for the critically ill. The Consensus for Worldwide End-of-Life Practice for Patients in Intensive Care Units (WELPICUS) study. Am J Respir Crit Care Med 190(8):855-866

60. Jesus JE, Allen MB, Michael GE, Donnino MW, Grossman SA, Hale CP, Breu AC, Bracey A, O'Connor JL, Fisher J (2013) Preferences for resuscitation and intubation among patients with do-not-resuscitate/do-not-intubate orders. Mayo Clin Proc 88(7):658-665 